\title{
County-Scale Spatial Variability of Macronutrient Availability Ratios in Paddy Soils
}

\author{
Mingkai Qu, ${ }^{1}$ Weidong Li, ${ }^{2}$ and Chuanrong Zhang ${ }^{2}$ \\ ${ }^{1}$ Key Laboratory of Soil Environment and Pollution Remediation, Institute of Soil Science, Chinese Academy of Sciences, \\ Nanjing 210008, China \\ ${ }^{2}$ Department of Geography and Center for Environmental Sciences and Engineering, University of Connecticut, Storrs, CT 06269, USA
}

Correspondence should be addressed to Weidong Li; weidongwoody@gmail.com

Received 22 June 2013; Revised 5 January 2014; Accepted 9 January 2014; Published 11 March 2014

Academic Editor: Davey Jones

Copyright (C) 2014 Mingkai Qu et al. This is an open access article distributed under the Creative Commons Attribution License, which permits unrestricted use, distribution, and reproduction in any medium, provided the original work is properly cited.

\begin{abstract}
Macronutrients $(\mathrm{N}, \mathrm{P}$, and $\mathrm{K}$ ) are essential to plants but also can be harmful to the environment when their available concentrations in soil are excessive. Availability ratios (available concentration/total concentration) of macronutrients may reflect their transforming potential between fixed and available forms in soil. Understanding their spatial distributions and impact factors can be, therefore, helpful to applying specific measures to modify the availability of macronutrients for agricultural and environmental management purposes. In this study, 636 topsoil samples $(0-15 \mathrm{~cm})$ were collected from paddy fields in Shayang County, Central China, for measuring soil properties. Factors influencing macronutrient availability ratios were investigated, and total and available concentrations of macronutrients were mapped using geostatistical method. Spatial distribution maps of macronutrient availability ratios were further derived. Results show that (1) availability of macronutrients is controlled by multiple factors, and (2) macronutrient availability ratios are spatially varied and may not always have spatial patterns identical to those of their corresponding total and available concentrations. These results are more useful than traditional soil macronutrient average content data for guiding site-specific field management for agricultural production and environmental protection.
\end{abstract}

\section{Introduction}

Soil macronutrients (i.e., Nitrogen (N), phosphorus (P), and potassium $(\mathrm{K})$ ) are essential to plants [1]. They provide nutrients necessary for plant growth, which are important to maintain ecosystems and high crop yields. However, macronutrients, particularly $\mathrm{N}$, and $\mathrm{P}$ can be potentially hazardous to water resources when their available components in soils are excessive, because available macronutrients can be transported off site in runoff due to rain or irrigation [2-4]. Improper or excessive fertilization has increasingly become a serious problem and the eutrophication problem caused by the losses of $\mathrm{N}$ and $\mathrm{P}$ from farmland to water bodies has caught people's attentions [5-7]. Therefore, proper management of soil $\mathrm{N}, \mathrm{P}$, and $\mathrm{K}$ is necessary to avoid deteriorating the environment while meeting the requirement of high crop productivity. In addition, reducing the losses of macronutrients from farmland also can save the costs spent on fertilizers.
Most of macronutrient contents exist in fixed forms in soils (e.g., contained in organic matter and minerals) and thus cannot be directly utilized by plants or transported to water bodies. Part of fertilizers applied to soil also can be fixed by soil and thus become unavailable to plants. This means that the total content of a macronutrient in soil is only a potentially available content in a long term, rather than its currently available content. Apparently the total content and the available content of a macronutrient are two different measures for the macronutrient in soil, and it is the availability ratio (i.e., available concentration/total concentration) that represents the potential effectiveness of a specific macronutrient in soil. That is to say, all the three indices may be necessary to understand the general situation of a macronutrient in soil. It is, therefore, important to investigate the spatial variability of availability ratios of soil macronutrients and corresponding controlling factors so that proper measures may be taken to modify the availability of the macronutrients for site-specific management. 
In addition to macronutrients, micronutrients and trace metals in soil also have similar problems, and their availability ratios in soil are also important indices for agricultural and environmental management. Recently, Wu et al. [8] studied the variability of $\mathrm{Cu}$ availability in soil and its relation to some soil properties in a $731 \mathrm{~km}^{2}$ region in southeast China. Their results showed that $\mathrm{Cu}$ availability ratio has a distributional trend similar to those of total $\mathrm{Cu}$ concentration and available $\mathrm{Cu}$ concentration, which are similar to each other. Zhang et al. [9] modeled the availability ratio of $\mathrm{Cu}$ in soil in Fuyang County, China, using the general regression neural network method. Although many studies on the spatial variability of soil N, P, and $\mathrm{K}$ were conducted in last several decades [10-20], most of them, however, were focused on their total contents or available contents in agricultural fields, and studies on the spatial distributions of their availability ratios in soils and corresponding impact factors at regional scales were rarely seen. Therefore, a study on the spatial variability of availability ratios of soil macronutrients and their impact factors in soil at a regional scale should be interesting and may provide valuable information to soil scientists and agricultural managers.

The objectives of this study were to (1) analyze the relationships between some soil properties and the availability of soil N, P, and K, (2) determine the controlling factors on the availability ratios of macronutrients, (3) map the spatial distributions of the indices of macronutrients in paddy soils at a regional scale, and (4) understand the characteristics of spatial patterns of macronutrient availability ratios. Shayang County in central China was selected as our case study area. This paper will provide an example for the availability ratio study of soil macronutrients, and results of such kind of studies will be helpful to decision making in applying concrete measures to modify the availability of soil macronutrients for site-specific agricultural management purposes.

\section{Materials and Methods}

2.1. Study Area. Shayang County, Hubei Province in central China was selected as the study area. The county is among the most developed regions for cropping in Hubei Province and is located in the Jianghan Plain, bounded by the longitudes $112^{\circ} 03^{\prime}$ and $112^{\circ} 43^{\prime}$ east, and the latitudes $30^{\circ} 23^{\prime}$ and $30^{\circ} 57^{\prime}$ north, with an area of $2044 \mathrm{~km}^{2}$. It belongs to the northern subtropical monsoonal climate zone, with a temperate-humid climate throughout the year and four distinct seasons. The average annual temperature is $16.1^{\circ} \mathrm{C}$ and the mean annual precipitation is $1025.6 \mathrm{~mm}$. In this region, paddy fields constitute the dominant land use type of arable lands.

2.2. Soil Sampling and Chemical Analysis. 636 topsoil samples were collected from paddy fields in 2007. The sampling scheme considered the distributional uniformity of samples and also ensured that all samples were located in paddy fields (Figure 1). All samples were taken in fall after harvest and before next cropping season to avoid the effect of fertilization during crop cultivation. For each soil sample, soils at 68 points within a small area of approximately 0.01 ha were collected from surface layers $(0-15 \mathrm{~cm})$ and then mixed

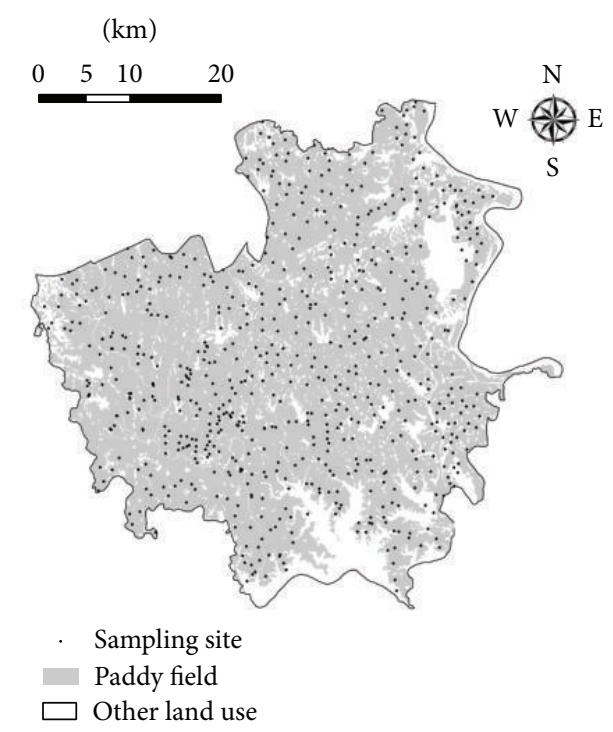

FIgURE 1: The study area and sampling sites.

and delivered to a laboratory for analysis. Exact sample locations were recorded using a hand-held global position system. All samples were air-dried at room temperature $\left(20-22^{\circ} \mathrm{C}\right)$, crushed, and sieved into soil particles less than $2 \mathrm{~mm}$. Portions of each sample (about $100 \mathrm{~g}$ ) were further ground and sieved through $0.149 \mathrm{~mm}$ mesh. The prepared soil samples were stored for chemical analysis.

Soil organic matter (SOM) was measured using the wet oxidation method at $180^{\circ} \mathrm{C}$ with a mixture of potassium dichromate and sulfuric acid [21]. Soil cation exchange capacity (CEC) was measured using $1.0 \mathrm{~mol} / \mathrm{L}$ ammonium acetate solution [21]. Soil $\mathrm{pH}$ was measured using a $\mathrm{pH}$ meter (Sartorius Basic pH meter PB-10) with a soil/water ratio of $1: 2.5$ [21]. Total nitrogen (TN) was determined by the Kjeldahl method with $\mathrm{H}_{2} \mathrm{SO}_{4}+\mathrm{H}_{2} \mathrm{O}_{2}$ digestion [22]. Available nitrogen (AN) was extracted using $2.0 \mathrm{~mol} / \mathrm{L}$ $\mathrm{KCl}$ [22]. Total phosphorus (TP) was extracted using melt sodium hydroxide and measured using the molybdenum stibium anticolor method [22]. Available phosphorus (AP) was extracted using $0.03 \mathrm{~mol} / \mathrm{L} \mathrm{NH}_{4} \mathrm{~F}$ and $0.025 \mathrm{~mol} / \mathrm{L} \mathrm{HCl}$ or $0.5 \mathrm{~mol} / \mathrm{L} \mathrm{NaHCO}_{3}$ (based on $\mathrm{pH}$ values), and analyzed using the molybdenum-blue method [22]. Total potassium (TK) was extracted using melt sodium hydroxide and then measured by flame emission spectrometry [22]. Available potassium (AK) was extracted using $1 \mathrm{~mol} / \mathrm{L} \mathrm{NH}_{4} \mathrm{OAc}$ and then measured by flame emission spectrometry [22]. Available $S$ (AS) was extracted using $500 \mathrm{mg}$ P/L Monocalcium phosphate $\left[\mathrm{Ca}\left(\mathrm{H}_{2} \mathrm{PO}_{4}\right)_{2}\right]$ and then determined by the turbidimetric method [23]. Available $\mathrm{Fe}(\mathrm{AFe})$, Available $\mathrm{Mn}$ $(\mathrm{AMn})$, Available $\mathrm{Cu}(\mathrm{ACu})$, and Available $\mathrm{Zn}(\mathrm{AZn})$ were extracted with diethylenetriaminepentaacetic acid (DTPA), and the extracted $\mathrm{AFe}, \mathrm{AMn}, \mathrm{ACu}$, and $\mathrm{AZn}$ were determined with flame atomic absorption spectrometry [23]. Available B $(\mathrm{AB})$ in soil was extracted with near-boiling deionized water and analyzed using a curcuma colorimetric procedure [23]. Quality control was based on the use of certified samples (GBW 07413) and analysis duplicates. 
TABLE 1: Summary statistics for macronutrient elements and other selected properties of paddy soils $(n=636)$.

\begin{tabular}{|c|c|c|c|c|c|c|c|c|}
\hline & Range & Minimum & Maximum & Mean & S.D. & Skewness & Kurtosis & C.V. $(\%)$ \\
\hline $\mathrm{N}$ availability ratio (\%) & 14.13 & 3.38 & 17.50 & 9.43 & 1.33 & 1.09 & 5.45 & 14.07 \\
\hline $\mathrm{P}$ availability ratio (\%) & 31.88 & 0.12 & 32.00 & 2.45 & 3.08 & 4.76 & 31.11 & 125.36 \\
\hline $\mathrm{K}$ availability ratio (\%) & 4.51 & 0.13 & 4.64 & 0.56 & 0.35 & 3.97 & 33.08 & 61.81 \\
\hline $\mathrm{TN}(\mathrm{g} / \mathrm{kg})$ & 1.87 & 0.48 & 2.35 & 1.44 & 0.31 & -0.37 & 0.14 & 21.69 \\
\hline $\mathrm{AN}(\mathrm{mg} / \mathrm{kg})$ & 181.00 & 45.00 & 226.00 & 134.64 & 28.15 & -0.45 & 0.18 & 20.91 \\
\hline $\mathrm{TP}(\mathrm{g} / \mathrm{kg})$ & 15.65 & 0.15 & 15.80 & 0.74 & 0.66 & 18.75 & 426.86 & 88.73 \\
\hline $\ln \mathrm{TP}$ & 4.66 & -1.90 & 2.76 & -0.41 & 0.46 & -0.29 & 4.07 & -112.04 \\
\hline $\mathrm{AP}(\mathrm{mg} / \mathrm{kg})$ & 93.00 & 2.00 & 95.00 & 14.03 & 11.21 & 2.55 & 9.73 & 79.89 \\
\hline $\ln \mathrm{AP}$ & 3.86 & 0.69 & 4.55 & 2.39 & 0.71 & -0.02 & -0.01 & 29.54 \\
\hline $\mathrm{TK}(\mathrm{g} / \mathrm{kg})$ & 28.36 & 7.33 & 35.69 & 19.96 & 3.41 & 0.91 & 1.87 & 17.07 \\
\hline $\ln \mathrm{TK}$ & 1.58 & 1.99 & 3.57 & 2.98 & 0.17 & -0.05 & 3.00 & 5.61 \\
\hline $\mathrm{AK}(\mathrm{mg} / \mathrm{kg})$ & 400.00 & 25.00 & 425.00 & 111.11 & 64.66 & 1.87 & 4.43 & 58.20 \\
\hline $\ln A K$ & 2.83 & 3.22 & 6.05 & 4.57 & 0.53 & 0.01 & 0.34 & 11.60 \\
\hline SOM $(\mathrm{g} / \mathrm{kg})$ & 35.65 & 4.89 & 40.54 & 23.11 & 5.31 & -0.60 & 0.07 & 22.97 \\
\hline $\mathrm{pH}$ & 3.00 & 5.10 & 8.10 & 6.61 & 0.67 & 0.76 & -0.19 & 10.08 \\
\hline $\mathrm{CEC}(\mathrm{cmol}(+) / \mathrm{kg})$ & 30.42 & 1.08 & 31.50 & 12.78 & 4.19 & 0.04 & 0.83 & 32.79 \\
\hline $\mathrm{AB}(\mathrm{mg} / \mathrm{kg})$ & 5.04 & 0.10 & 5.14 & 0.64 & 0.55 & 3.59 & 18.16 & 86.73 \\
\hline $\mathrm{ACu}(\mathrm{mg} / \mathrm{kg})$ & 5.28 & 0.61 & 5.89 & 2.70 & 0.89 & 0.45 & -0.11 & 33.08 \\
\hline $\mathrm{AZn}(\mathrm{mg} / \mathrm{kg})$ & 8.39 & 0.12 & 8.51 & 1.38 & 0.73 & 2.40 & 15.20 & 52.58 \\
\hline $\mathrm{AMn}(\mathrm{mg} / \mathrm{kg})$ & 545.41 & 5.79 & 551.20 & 33.08 & 25.79 & 12.92 & 256.27 & 77.96 \\
\hline $\mathrm{AFe}(\mathrm{mg} / \mathrm{kg})$ & 349.74 & 6.03 & 355.77 & 118.78 & 89.18 & 0.67 & -0.99 & 75.08 \\
\hline $\mathrm{AS}(\mathrm{mg} / \mathrm{kg})$ & 182.65 & 7.85 & 190.50 & 41.25 & 21.99 & 1.42 & 4.58 & 53.30 \\
\hline
\end{tabular}

2.3. Availability Ratio. The availability ratio of a soil macronutrient $(\mathrm{N}, \mathrm{P}$, or $\mathrm{K})$ at a given location is calculated using the following equation:

$$
R=\frac{A(\mathbf{u})}{T(\mathbf{u}) \times 1000} \times 100,
$$

where $R$ represents the availability ratio (\%); $\mathbf{u}$ refers to a specific location; $A(\mathbf{u})$ is the available concentration of a soil macronutrient at location $\mathbf{u}$ with a unit of $\mathrm{mg} / \mathrm{kg} ; T(\mathbf{u})$ is the total concentration of the soil macronutrient at location $\mathbf{u}$ with a unit of $\mathrm{g} / \mathrm{kg}$.

2.4. Correlation Analysis. Correlation analysis was conducted to reveal relationships between availability ratios of N, P, and $\mathrm{K}$ and selected soil properties (i.e., TN, AN, TP, AP, TK, $\mathrm{AK}, \mathrm{AFe}, \mathrm{AMn}, \mathrm{AS}, \mathrm{ACu}, \mathrm{AZn}, \mathrm{AB}, \mathrm{pH}, \mathrm{SOM}$, and CEC). The significant level reported (i.e., $P<0.01$ ) was based on Pearson's correlation coefficients. The software used is SPSS R13.0 for Windows.

We also performed stepwise regression analysis to select the main factors that affect the availability ratios of soil $\mathrm{N}, \mathrm{P}$, and $\mathrm{K}$ using the SPSS R13.0 software. Usually many possible explanatory variables may exist in a data set. Through a stepwise regression process, explanatory variables can be examined one by one, and the one that explains the most variation in the dependent variable will be added to the model at each step. When adding an extra variable will make no significant improvement in the amount of explained variation, the regression process will stop [24].
2.5. Geostatistical Analysis. Geostatistics provides methods to predict values at unsampled locations from values at sampled locations by taking into account the spatial correlation of sampled points. The variogram, the spatial measure for kriging, is an effective tool for evaluating spatial variability. The variogram may describe the spatial autocorrelation structure of a continuous variable and provide some insight into possible factors that affect data distribution. Spatial patterns of soil attributes following intrinsic stationarity can be described using variogram models [25].

In this study, no apparent anisotropy was found for any studied variable through experimental variograms. So, all experimental variograms were in isotropic form and were fitted using basic math models, such as the spherical and exponential models, for kriging interpolation. Ordinary kriging was chosen to create the spatial distribution maps of soil $\mathrm{N}, \mathrm{P}$, and $\mathrm{K}$ contents, with the maximum search radius being set to the autocorrelation range of the corresponding variable. The interpolated grid had a resolution of $200.79 \mathrm{~m} \times$ $200.79 \mathrm{~m}$. Readers may see Chiles and Delfiner [26] for detailed description of kriging and the variogram. The Software GSLIB was used to conduct all the geostatistical work.

\section{Results and Discussions}

3.1. Correlation Analysis and Controlling Factors. The summary statistics of soil N, P, and $\mathrm{K}$ and selected soil properties ( $\mathrm{pH}, \mathrm{SOM}, \mathrm{CEC}, \mathrm{AFe}, \mathrm{AMn}, \mathrm{AS}, \mathrm{ACu}, \mathrm{AZn}$, and $\mathrm{AB}$ ) are listed in Table 1. The coefficients of variation (CVs) for availability ratios of $\mathrm{N}, \mathrm{P}$, and $\mathrm{K}$ are $14.07 \%, 125.36 \%$, and 
$61.8 \%$, respectively. This means that the availability ratios of $\mathrm{P}$ and $\mathrm{K}$ have much larger variability than those of $\mathrm{N}$ in the study area. This situation may be caused by some extrinsic factors such as different fertilizer applications and seasonal cropping, which have stronger impacts on available $\mathrm{P}$ and $\mathrm{K}$. In fact, TP, AP, and AK indeed have large $\mathrm{CV}$ values. Table 1 also shows that CEC, AB, ACu, AZn, AMn, AFe, and AS have relatively high CV values ( $>25 \%$ ), reflecting the complex heterogeneity of paddy soils in the study area.

Pearson's correlation coefficients were calculated for each variable to reveal the relationships between the availability ratios of macronutrients and the selected soil properties (see Table 2). Apparently, the availability ratio of every macronutrient is negatively correlated with its total content and positively correlated with its available content, as shown in Table 2. However, the correlation situations between availability ratio and total and available contents are different for different macronutrients. The availability ratio of $\mathrm{K}$ has a very weak negative correlation with TK and a very strong positive correlation with AK. This implies that the TK content in soil is relatively stable over the study area, and a considerable amount of AK may come from outside input. The strong positive correlation between $\mathrm{P}$ availability ratio and $\mathrm{AP}$ also indicates that outside input may contribute a lot to soil AP. However, the availability ratio of $\mathrm{N}$ does not have such characteristic, and it is relatively more strongly impacted by $\mathrm{TN}$. This means that most AN in paddy soils may come from $\mathrm{SOM}$, and this point is supported by the strong positive correlation between AN and SOM. In general, the available contents of $\mathrm{K}$ and $\mathrm{P}$ are more decisive to their availability ratios; on the contrary, the total content of $\mathrm{N}$ has more impact on its availability ratio.

Checking the correlation situations of other soil properties with $\mathrm{N}, \mathrm{P}$, and $\mathrm{K}$, one can find that these selected properties each have similar positive or negative influences on AN and TN (Table 2). This may explain why the availability ratio of $\mathrm{N}$ is less correlated with other soil properties (the largest correlation coefficient is with SOM, which is $-0.135, P<0.01)$. However, the selected soil properties have much stronger correlations with AP and TK than with $\mathrm{TP}$ and $\mathrm{AK}$, although these correlations are mostly weaker than those with TN and AN. For example, both $\mathrm{pH}$ and $\mathrm{AB}$ show strong correlations with TK but weak correlations with AK. The correlations of availability ratios of N, P, and $\mathrm{K}$ with the selected soil properties are generally not strong. The availability ratio of $\mathrm{P}$ is moderately correlated with $\mathrm{ACu}$ and AFe $\left(r_{s}=0.261\right.$ and 0.266 , respectively, $\left.P<0.01\right)$. The availability ratio of $\mathrm{K}$ is moderately correlated with CEC and AZn $\left(r_{s}=0.252\right.$ and 0.367 , respectively, $\left.P<0.01\right)$.

Stepwise regression analysis was performed for the availability ratios of $\mathrm{N}, \mathrm{P}$, and $\mathrm{K}$, by using all of other soil properties as independent variables. The results are given as follows:

$$
\begin{aligned}
& Y_{(\mathrm{N} \text { availability ratio \%) }} \\
& =8.669-7.063 X_{(\mathrm{TN})}+0.075 X_{(\mathrm{AN})}+0.106 X_{(\mathrm{PH})} \\
& +0.004 X_{(\mathrm{AP})}+0.061 X_{(\mathrm{AZn})}+0.069 X_{(\mathrm{AB})}, \\
& \quad\left(R^{2}=0.91\right),
\end{aligned}
$$

$$
\begin{aligned}
Y_{(\mathrm{P} \text { availability ratio \% })} & \\
= & -2.533+0.203 X_{(\mathrm{AP})}-0.992 X_{(\mathrm{TP})} \\
& +0.004 X_{(\mathrm{AFe})}+0.359 X_{(\mathrm{PH})}, \quad\left(R^{2}=0.86\right), \\
Y_{(\mathrm{K} \text { availability ratio \% })} & \\
= & 0.497+0.005 X_{(\mathrm{AK})}-0.036 X_{(\mathrm{TK})} \\
& +0.026 X_{(\mathrm{PH})}+0.027 X_{(\mathrm{AB})}, \quad\left(R^{2}=0.93\right) .
\end{aligned}
$$

The coefficients of determination $\left(R^{2}\right)$ provided after each of above regression models indicate that all of three multiple linear regression models are well fitted by sample data. It can be seen that the availability ratios of $\mathrm{N}, \mathrm{P}$, and $\mathrm{K}$ are all influenced by multiple factors which are also interrelated with each other. Stepwise regression could find major controlling factors. Above equations indicate that the availability ratio of $\mathrm{N}$ is mainly controlled by $\mathrm{TN}, \mathrm{AN}, \mathrm{pH}, \mathrm{AP}, \mathrm{AZn}$, and $\mathrm{AB}$, the availability ratio of $\mathrm{P}$ mainly depends on $\mathrm{AP}, \mathrm{TP}$, $\mathrm{AFe}$, and $\mathrm{pH}$, and that of $\mathrm{K}$ is mainly contributed by $\mathrm{AK}$, $\mathrm{TK}, \mathrm{pH}$, and $\mathrm{AB}$. These results are not fully consistent with the Pearson's correlation coefficients in Table 2. For example, $\mathrm{pH}$ appears to be an important positive contributing factor to the availability ratios of all macronutrients here; however, its correlation coefficients with these availability ratios are quite small in absolute values and are not all positive. The reason may be that a Pearson's correlation coefficient only reflects the linear correlation between two variables, but a regression coefficient in a multiple linear regression model is also related with other predictor variables and impacted by the multicollinearity problem.

3.2. Spatial Structure and Distributional Patterns. Geostatistical methods were used to analyze the spatial correlation structures of the total and available contents of N, P, and $\mathrm{K}$ in soil and spatially estimate their values at unsampled locations. Because kriging assumes the normal distribution for each estimated variable, it is necessary to check whether the total and available contents of N, P, and $\mathrm{K}$ in soil samples are approximately normally distributed or not. From Table 1, one can see that the skewness and kurtosis indices of TN and $\mathrm{AN}$ are close to the standard value of 0 , but those of TP, $\mathrm{AP}, \mathrm{TK}$, and $\mathrm{AK}$ are not. In this study, natural logarithmic transformation was used to reduce the skewness of the data distributions of $\mathrm{P}$ and $\mathrm{K}$. The histograms of $\mathrm{N}, \mathrm{P}$, and $\mathrm{K}$ data used for geostatistical interpolation are shown in Figure 2. One can see that they tend to be normally distributed.

Experimental variograms and fitted models for $\mathrm{TN}$, $\mathrm{AN}, \ln (\mathrm{TP}), \ln (\mathrm{AP}), \ln (\mathrm{TK})$, and $\ln (\mathrm{AK})$ are presented in Figure 3. Spherical models are chosen for $\mathrm{TN}$ and $\ln (\mathrm{AK})$, Gaussian models for $\ln (\mathrm{TP})$, and $\ln (\mathrm{AP})$, and exponential models for $\mathrm{AN}$ and $\ln (\mathrm{TK})$. The nugget/sill ratio $\left(C_{0} /(C+\right.$ $\left.C_{0}\right)$ ) may be used as a criterion to reflect the spatial autodependency of a variable. Ratio values lower than $25 \%$, between $25 \%$ and $75 \%$, and higher than $75 \%$ correspond to strong, moderate, and weak spatial dependencies, 


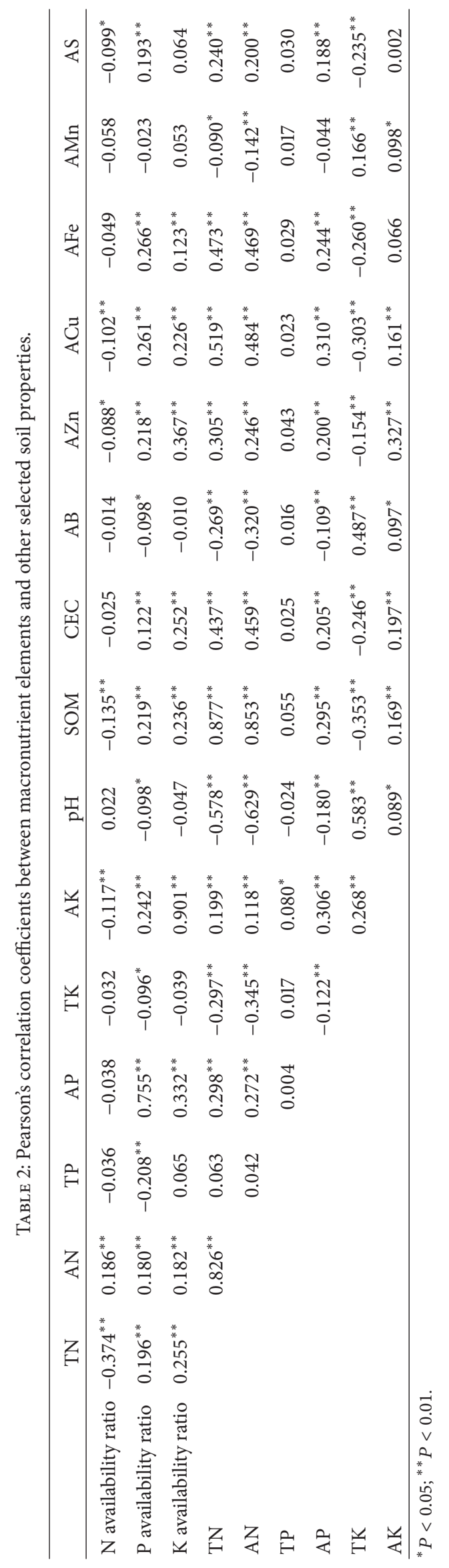




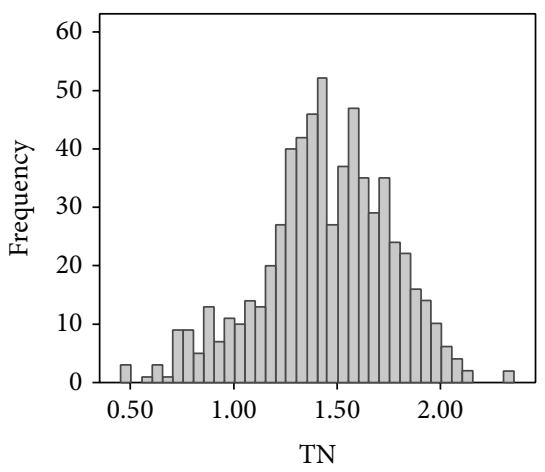

(a)

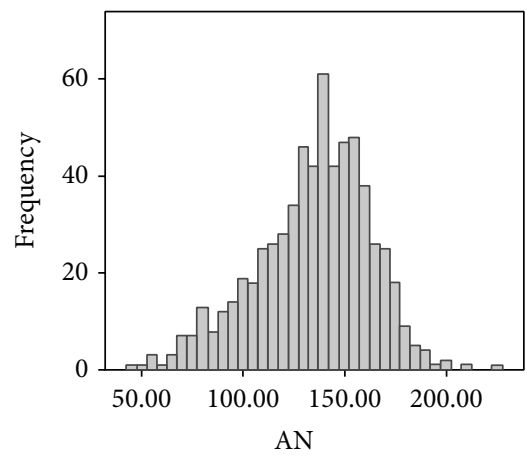

(d)

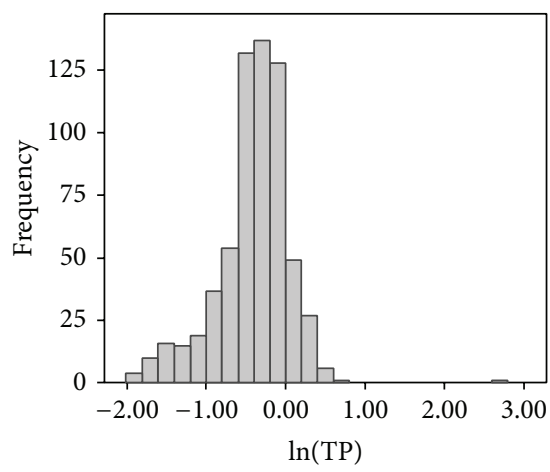

(b)

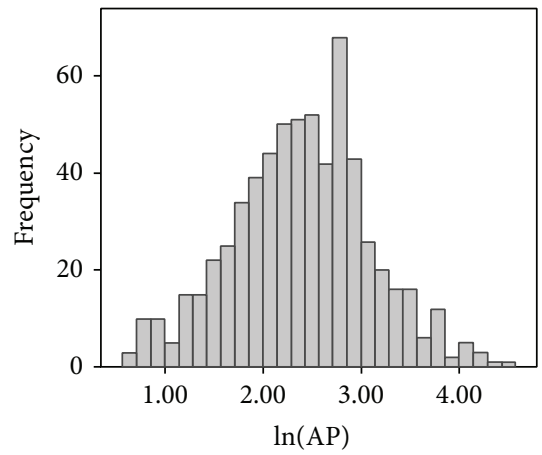

(e)

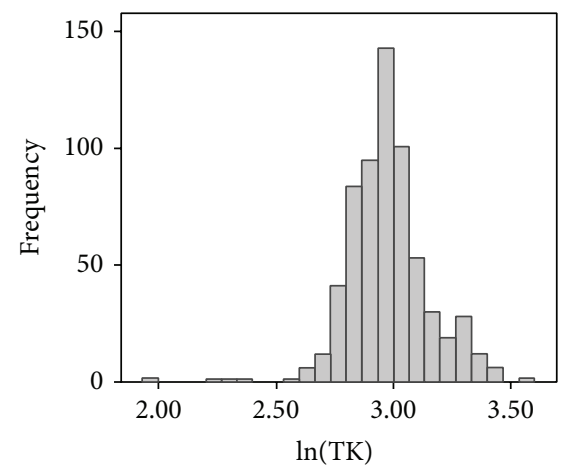

(c)

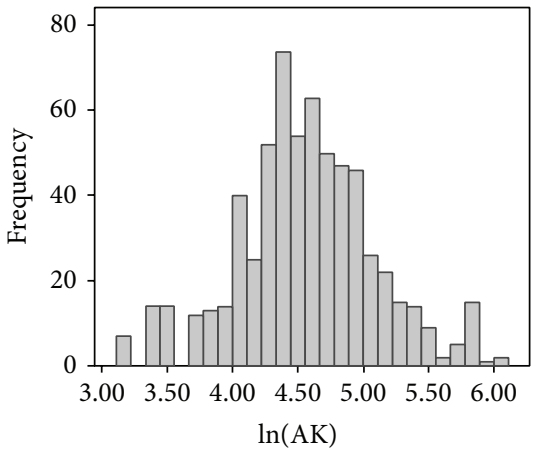

(f)

Figure 2: Histograms of TN (a), $\ln (\mathrm{TP})(\mathrm{b}), \ln (\mathrm{TK})(\mathrm{c}), \mathrm{AN}(\mathrm{d}), \ln (\mathrm{AP})(\mathrm{e})$, and $\ln (\mathrm{AK})$ (f).

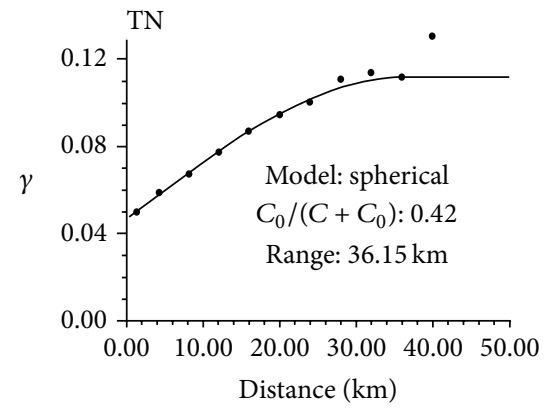

(a)

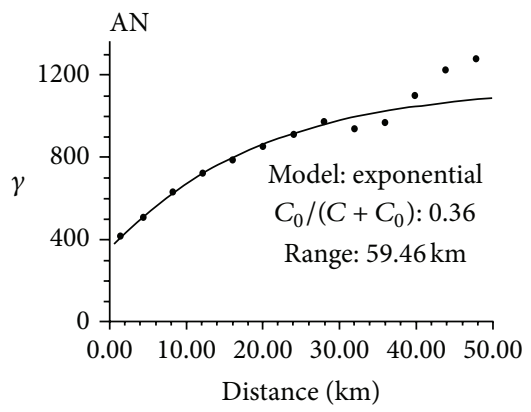

(d)

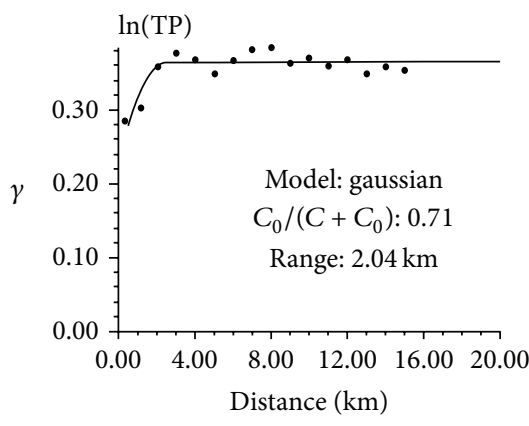

(b)

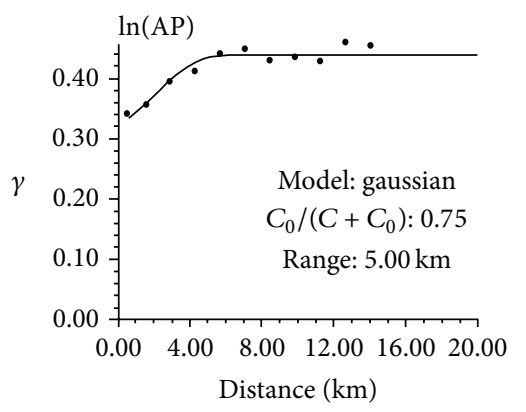

(e)

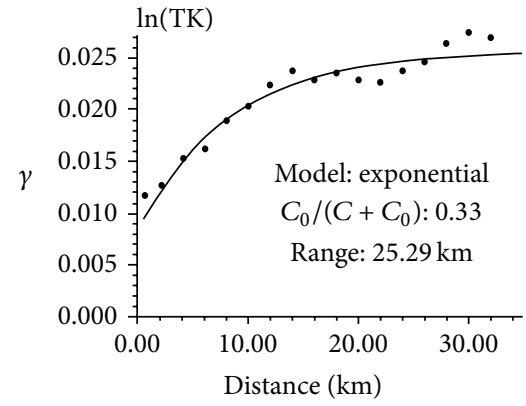

(c)

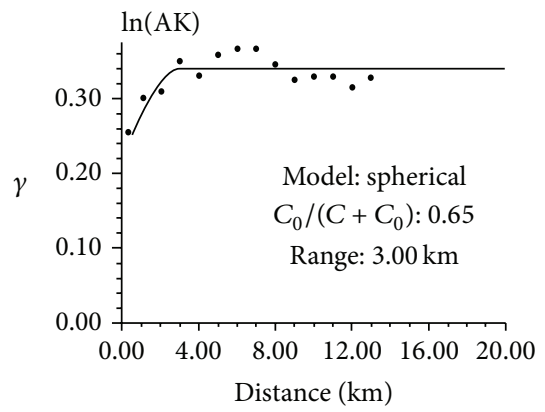

(f)

Figure 3: Experimental variograms of TN (a), $\ln (\mathrm{TP})(\mathrm{b}), \ln (\mathrm{TK})(\mathrm{c}), \mathrm{AN}(\mathrm{d}), \ln (\mathrm{AP})(\mathrm{e})$, and $\ln (\mathrm{AK})(\mathrm{f})$, and their fitted models. 


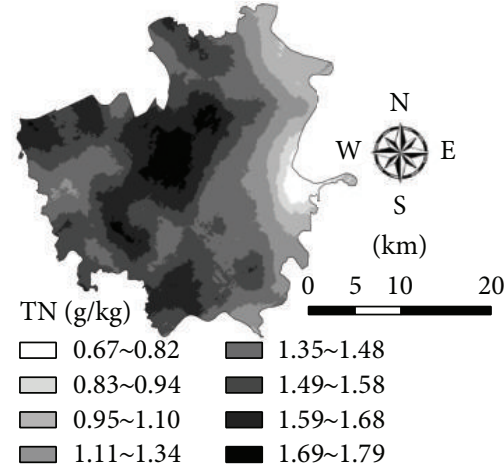

(a)

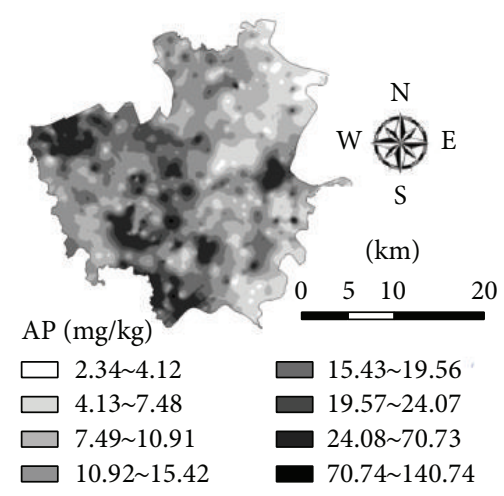

(d)

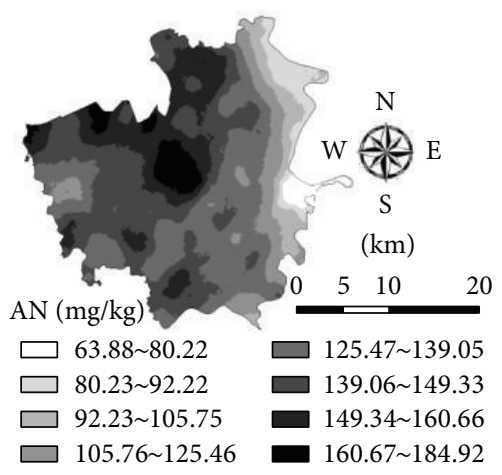

(b)

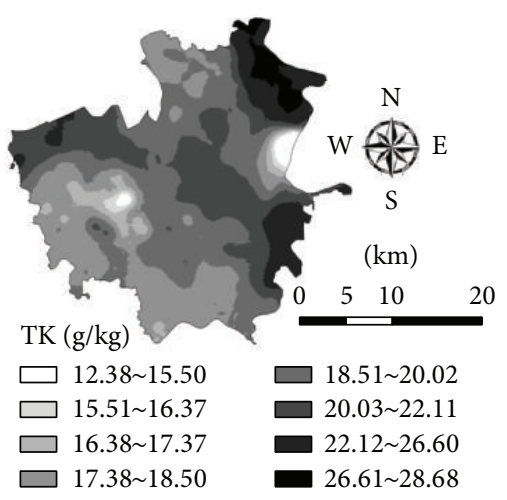

(e)

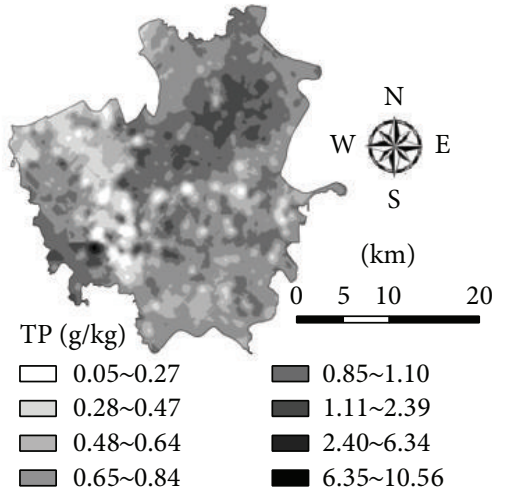

(c)

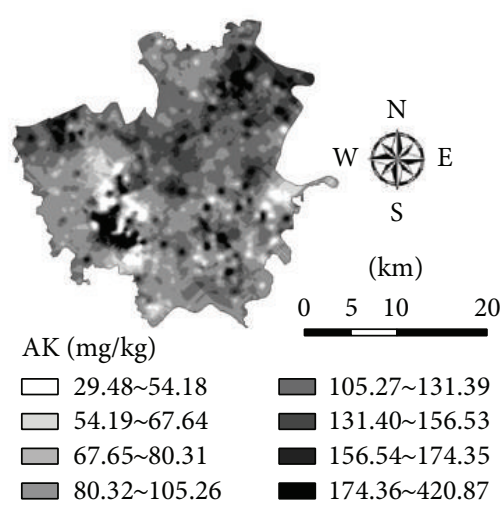

(f)

FIGURE 4: Spatial distribution maps of TN (a), AN (b), TP (c), AP (d), TK (e), and AK (f), interpolated by ordinary kriging.

respectively [11]. The nugget/sill ratios of variogram models for $\mathrm{TN}, \mathrm{AN}, \ln (\mathrm{TP}), \ln (\mathrm{AP}), \ln (\mathrm{TK})$, and $\ln (\mathrm{AK})$ all fall between $25 \%$ and $75 \%$, which indicates that all of the six properties exhibit moderate spatial dependency. According to Cambardella et al. [11], these spatial autodependencies may be attributed to both intrinsic factors such as other soil properties and extrinsic factors such as human activities. The correlation range measures the spatial separate distance within which data are autocorrelated [27]. The approximate correlation ranges for $\mathrm{TN}, \mathrm{AN}, \ln (\mathrm{TP}), \ln (\mathrm{AP}), \ln (\mathrm{TK})$, and $\ln (\mathrm{AK})$ are $36.15 \mathrm{~km}, 59.46 \mathrm{~km}, 2.04 \mathrm{~km}, 5.00 \mathrm{~km}, 25.29 \mathrm{~km}$, and $3.00 \mathrm{~km}$, respectively. Apparently, AN, TN, and TK are autocorrelated in longer ranges than TP, AP, and $\mathrm{AK}$ are. This result is consistent with their $\mathrm{CV}$ values. This may imply that $\mathrm{TP}, \mathrm{AP}$, and AK contents are more sensitive to extrinsic factors such as fertilization.

To map the spatial distributions of TN, AN, TP, AP, TK, and $A K$, we used ordinary kriging to interpolate their respective sample data (Figure 4). After the spatial distribution maps of the total and available contents of a macronutrient were obtained, its availability ratio map could be further derived from the total content map and available content map by using (1) (i.e., at each spatial location, availability ratio = available content/total content). The spatial maps of TN and AN (Figures 4(a) and 4(b)) show similar patterns. This may be why TN and AN are strongly correlated $\left(r_{s}=0.826\right.$,
$P<0.01)$. However, the spatial map of the availability ratio of $\mathrm{N}$ (Figure 5(a)) shows a different spatial pattern. This means that the contents of AN and TN are not spatially proportional and they are impacted by other factors with different degrees. $\mathrm{AP}$ and the availability ratio of $\mathrm{P}$ exhibit similar spatial trends (see Figures 4(d) and 5(b)). This should be caused by the strong correlation $\left(r_{s}=0.755, P<0.01\right)$ between these two variables. Because AP and TP have almost no correlation (see Table 2), consequently the spatial pattern of $\mathrm{P}$ availability ratio is quite different from that of TP. The spatial distribution maps of $\mathrm{AK}$ and $\mathrm{K}$ availability ratio also show similar spatial patterns, which should be caused by their strong (nearly linear) correlation $\left(r_{s}=0.901, P<0.01\right)$ (see Figures $4(\mathrm{f}$ ) and 5(c)). The correlation between AK and TK is not strong, which may be why they have different spatial patterns and the spatial pattern of $K$ availability ratio is very different from that of TK.

The short autocorrelation ranges of $\mathrm{TP}, \mathrm{AP}$, and $\mathrm{AK}$ are reflected on their spatial distribution maps with fragmentary patterns and this characteristic is further propagated to the spatial distribution maps of the availability ratios of $\mathrm{P}$ and $\mathrm{K}$. Consequently, one can see in Figure 5 that the spatial distributional characteristics of the availability ratios of $\mathrm{N}$, $\mathrm{P}$, and $\mathrm{K}$ are very different: (i) the availability ratio of $\mathrm{N}$ changes smoothly with large patches while that of $\mathrm{K}$ and $\mathrm{P}$ vary abruptly as small pieces or spots in the study area; (ii) 


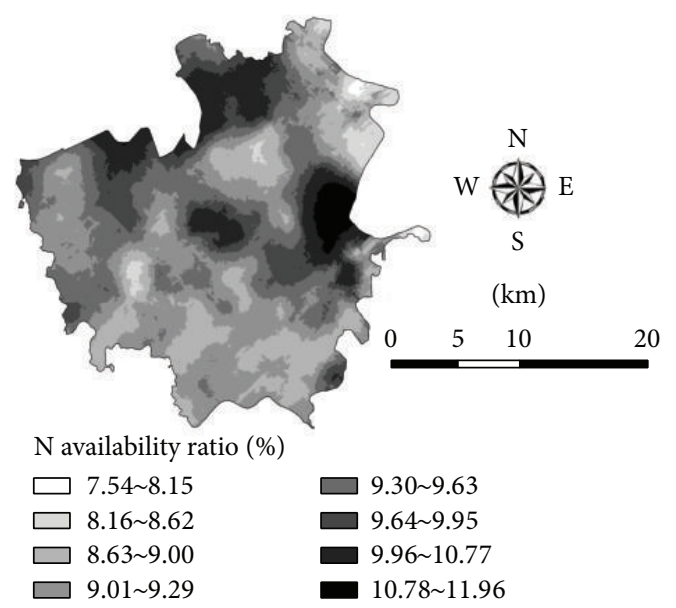

(a)

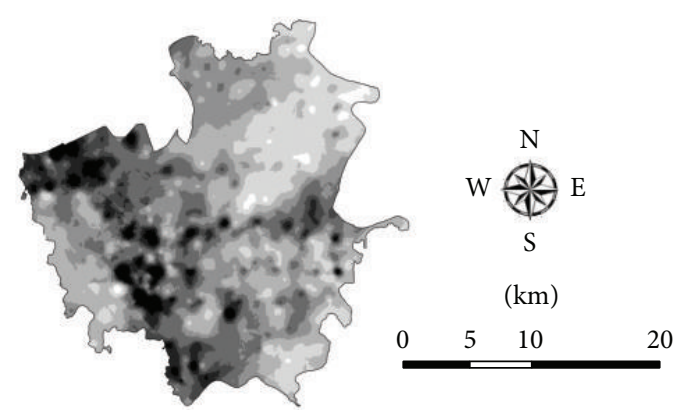

$P$ availability ratio (\%)

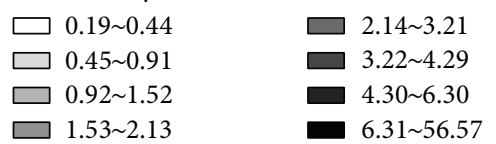

(b)

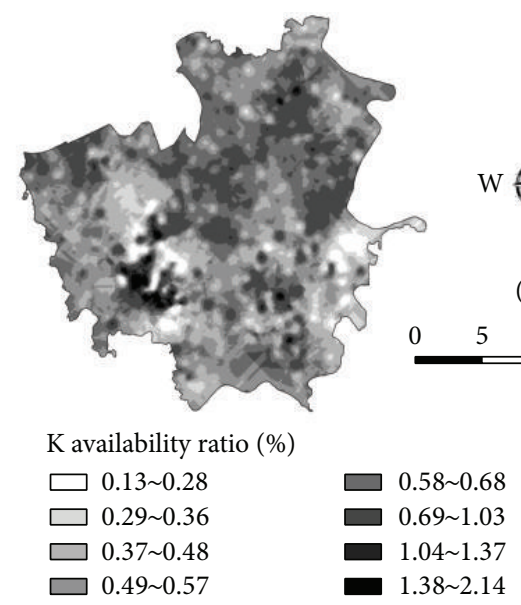

(c)

Figure 5: Spatial distribution maps of availability ratios of $\mathrm{N}(\mathrm{a}), \mathrm{P}(\mathrm{b})$, and $\mathrm{K}(\mathrm{c})$. Note that (a) is derived from Figures 4(a) and 4(b), (b) is derived from Figures 4(c) and 4(d), and (c) is derived from Figures 4(e) and 4(f).

high availability ratio values of $\mathrm{N}$ mainly appear in several subareas in the east and north of the study area, and high availability ratio values of $\mathrm{P}$ mainly occur as a series of spots along a strip in the southwest, while high availability ratio values of $\mathrm{K}$ mainly emerge as isolated spots, often bordered with very low values. These availability ratio maps clearly show where a macronutrient has low availability and where its availability is high. Thus, concrete measures might be taken to increase the low availability or decrease the high availability of a macronutrient in a specific area to meet the requirements of agricultural production and environmental protection. For example, changing soil pH may help change the efficiency of soil nitrogen to be absorbed by plants.

It should be noted that the data value ranges (from minimum value to maximum value in each legend) in the legends of Figures 4 and 5 are not consistent with the corresponding value ranges of sample data provided in Table 2. The major reason may be that the locations of interpolated grid values by kriging for mapping do not overlap those of sample data, thus the legends show only the value ranges of interpolated data and sample data values are ignored in the maps.

\section{Conclusion}

The spatial variability of soil N, P, and K and their availability ratios in paddy soils in a county were explored. After a long history of various land management, the spatial variability of $\mathrm{N}, \mathrm{P}$, and $\mathrm{K}$ and their availability ratios in soils are not only dependent on soil parent materials but also impacted by anthropogenic activities. Statistical analysis shows that the availability ratios of $\mathrm{P}$ and $\mathrm{K}$ have larger variation than that of $\mathrm{N}$ in the study area, probably due to the heterogeneous land use and management. The contents of TN, AN, and TK in paddy fields have relatively longer correlation ranges than those of TP, AP, and AK. The availability ratios of N, P, and K are all affected by multiple factors that are also interrelated. The main factors controlling the availability ratios of $\mathrm{N}, \mathrm{P}$, and $\mathrm{K}$ were determined using stepwise regression analysis. $\mathrm{N}$ 
availability ratio is mainly related to $\mathrm{TN}, \mathrm{AN}, \mathrm{pH}, \mathrm{AP}, \mathrm{AZn}$, and $\mathrm{AB} ; \mathrm{P}$ availability ratio is mainly controlled by $\mathrm{AP}, \mathrm{TP}$, $\mathrm{AFe}$, and $\mathrm{pH}$; and $\mathrm{K}$ availability ratio is mainly affected by $\mathrm{AK}$, $\mathrm{TK}, \mathrm{pH}$, and $\mathrm{AB}$.

TN and AN contents have similar spatial patterns, but $\mathrm{N}$ availability ratio has a different spatial pattern; however, the spatial patterns of availability ratios of $\mathrm{P}$ and $\mathrm{K}$ are only similar to those of their available components (i.e., AP and $\mathrm{AK}$ ), respectively. Availability ratios of nutrients in soil may reflect soil's nutrient holding (or fixing) ability. The different spatial variability characteristics among the total content, the available content, and the availability ratio of each macronutrient indicate that these three indices are all useful to reflect the general situation of the macronutrient in soil and their spatial maps are all useful data for agricultural and environmental management.

Because the availability ratio of a macronutrient is related with its availability (or efficiency) to plants and its risk of loss into deep soil or water body, proper adjustment of macronutrient availability ratios in soil through some measures (e.g., fertilization, liming to change soil $\mathrm{pH}$ ) may be helpful to improving agricultural productivity and reducing environmental hazards. Therefore, spatial distribution maps of macronutrient availability ratios may provide useful information to guide site-specific soil management.

\section{Conflict of Interests}

The authors declare that there is no conflict of interests regarding the publication of this paper.

\section{Acknowledgment}

This work was partially supported by China Postdoctoral Science Foundation (Funded Project 2013M530273).

\section{References}

[1] H. Marschner, Mineral Nutrition of Higher Plants, Academic Press, London, UK, 1995.

[2] P. Phupaibul, C. Chitbuntanorm, N. Chinoim, P. Kangyawongha, and T. Matoh, "Phosphorus accumulation in soils and nitrate contamination in underground water under exportoriented asparagus farming in Nong Ngu Lauem Village, Nakhon Pathom Province, Thailand," Soil Science and Plant Nutrition, vol. 50, no. 3, pp. 385-393, 2004.

[3] X. T. Ju, C. L. Kou, P. Christie, Z. X. Dou, and F. S. Zhang, "Changes in the soil environment from excessive application of fertilizers and manures to two contrasting intensive cropping systems on the North China Plain," Environmental Pollution, vol. 145, no. 2, pp. 497-506, 2007.

[4] V. H. Smith, G. D. Tilman, and J. C. Nekola, "Eutrophication: impacts of excess nutrient inputs on freshwater, marine, and terrestrial ecosystems," Environmental Pollution, vol. 100, no. 13, pp. 179-196, 1998.

[5] A. Sharpley, "Identifying sites vulnerable to phosphorus loss in agricultural runoff," Journal of Environmental Quality, vol. 24, no. 5, pp. 947-951, 1995.

[6] M. N. Almasri and J. J. Kaluarachchi, "Assessment and management of long-term nitrate pollution of ground water in agriculture-dominated watersheds," Journal of Hydrology, vol. 295, no. 1-4, pp. 225-245, 2004.

[7] Y. Chen, B. H. He, X. L. Zhao, and L. Zhang, "Effect of soil erosion and water loss in Farmland on water eutrophication in Xiaojiang River Basin," Journal of Soil and Water Conservation, vol. 24, pp. 31-43, 2010.

[8] C. F. Wu, Y. M. Luo, and L. M. Zhang, "Variability of copper availability in paddy fields in relation to selected soil properties in southeast China," Geoderma, vol. 156, no. 3-4, pp. 200-206, 2010.

[9] X. Y. Zhang, Z. Y. Ling, T. Y. Zhong, and K. Wang, "Simulation of the availability index of soil copper content using general regression neural network," Environmental Earth Sciences, vol. 64, no. 7, pp. 1697-1702, 2011.

[10] J. G. White and R. J. Zasoski, "Mapping soil micronutrients," Field Crops Research, vol. 60, no. 1-2, pp. 11-26, 1999.

[11] C. A. Cambardella, T. B. Moorman, J. M. Novak et al., "Fieldscale variability of soil properties in central Iowa soils," Soil Science Society of America Journal, vol. 58, no. 5, pp. 1501-1511, 1994.

[12] Y. L. Bai, J. Y. Jin, L. P. Yang, and M. Z. Liang, "Research on the subarea management model of soil nutrients by GIS," Scientia Agricultura Sinica, vol. 34, pp. 46-50, 2001 (Chinese).

[13] R. Corstanje, S. Grunwald, K. R. Reddy, T. Z. Osborne, and S. Newman, "Assessment of the spatial distribution of soil properties in a Northern Everglades marsh," Journal of Environmental Quality, vol. 35, no. 3, pp. 938-949, 2006.

[14] K. W. Holmes, P. C. Kyriakidis, O. A. Chadwick, J. V. Soares, and D. A. Roberts, "Multi-scale variability in tropical soil nutrients following land-cover change," Biogeochemistry, vol. 74, no. 2, pp. 173-203, 2005.

[15] S. W. Huang, J. Y. Jin, L. P. Yang, Y. L. Bai, and C. H. Li, "Spatial variability of nitrate in cabbage and nitrate-N in soil," Soil Science, vol. 169, no. 9, pp. 640-649, 2004.

[16] S. W. Huang, J. Y. Jin, L. P. Yang, and Y. L. Bai, "Spatial variability of soil nutrients and influencing factors in a vegetable production area of Hebei Province in China," Nutrient Cycling in Agroecosystems, vol. 75, no. 1-3, pp. 201-212, 2006.

[17] B. Huang, W. X. Sun, Y. C. Zhao et al., “Temporal and spatial variability of soil organic matter and total nitrogen in an agricultural ecosystem as affected by farming practices," Geoderma, vol. 139, no. 3-4, pp. 336-345, 2007.

[18] T. J. Sauer and D. W. Meek, "Spatial variation of plant-available phosphorus in pastures with contrasting management," Soil Science Society of America Journal, vol. 67, no. 3, pp. 826-836, 2003.

[19] Y. C. Wei, Y. L. Bai, J. Y. Jin, F. Zhang, L. P. Zhang, and X. Q. Liu, "Spatial variability of soil chemical properties in the reclaiming marine foreland to yellow sea of China," Agricultural Sciences in China, vol. 8, no. 9, pp. 1103-1111, 2009.

[20] Y. Zhao, X. Xu, J. L. Darilek, B. Huang, W. Sun, and X. Shi, "Spatial variability assessment of soil nutrients in an intense agricultural area, a case study of Rugao County in Yangtze River Delta Region, China," Environmental Geology, vol. 57, no. 5, pp. 1089-1102, 2009.

[21] Agricultural Chemistry Committee of China, Conventional Methods of Soil and Agricultural Chemistry Analysis (in Chinese), Science Press, Beijing, China, 1983.

[22] H. T. Kim, Soil Sampling, Preparation, and Analysis, CRC, Florida, Pa, USA, 2005. 
[23] R. K. Lu, Analysis Method of Soil and Agricultural Chemistry (in Chinese), China Agricultural Science and Technology Press, Beijing, China, 2000.

[24] D. G. Altman, Practical Statistics for Medical Research, Chapman \& Hall, London, UK, 1991.

[25] R. Webster and M. A. Oliver, Statistical Methods in Soil and Land Resource Survey, Oxford University Press, London, UK, 1990.

[26] J.-P. Chiles and P. Delfiner, Geostatistics: Modeling Spatial Uncertainty, Wiley, New York, NY, USA, 1999.

[27] M. D. Cahn, J. W. Hummel, and B. H. Brouer, "Spatial analysis of soil fertility for site-specific crop management," Soil Science Society of America Journal, vol. 58, no. 4, pp. 1240-1248, 1994. 

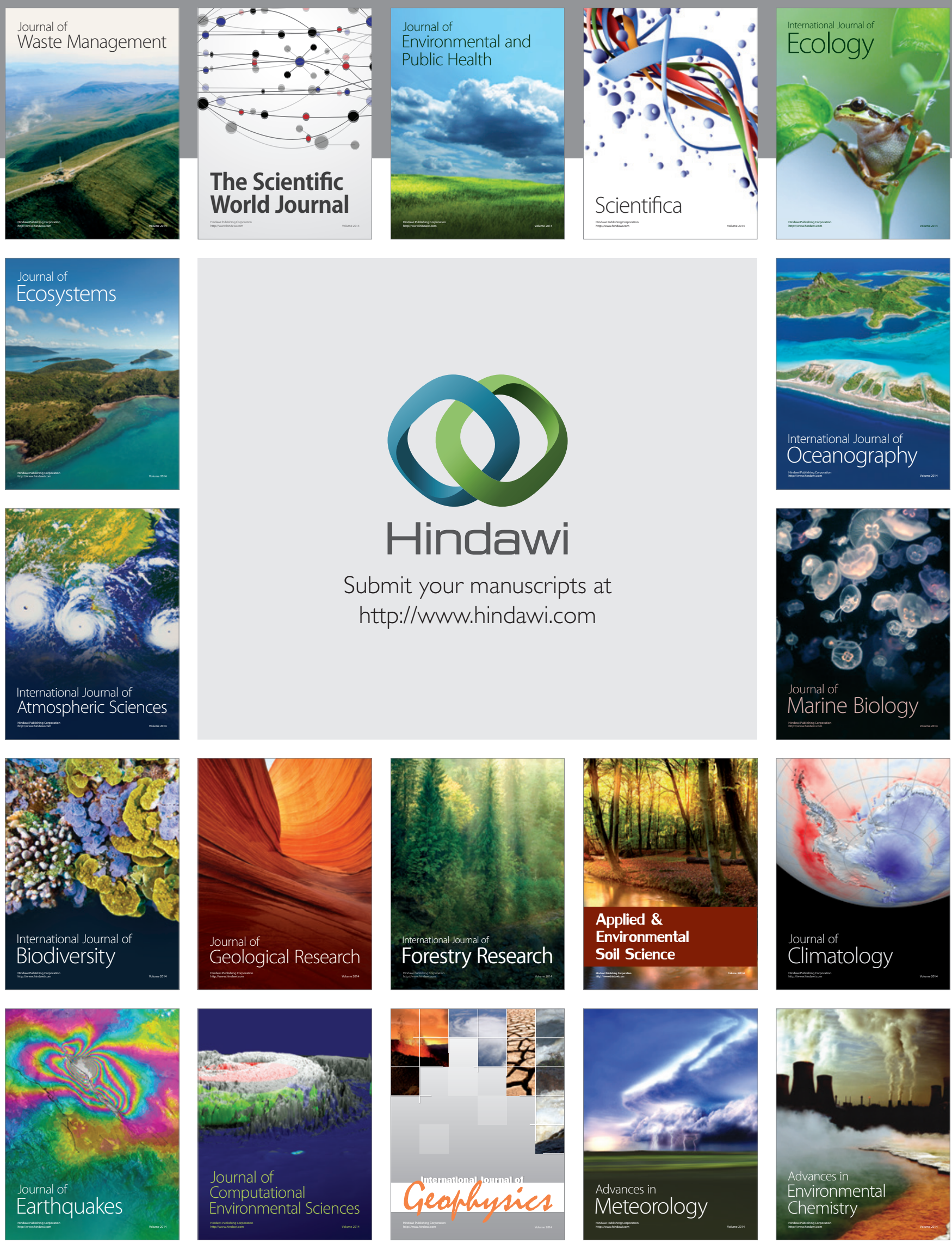